\title{
What is so Practical about Theory? Lewin Revisited
}

\section{LLOYD E. SANDELANDS}

"There is nothing so practical as a good theory" - Kurt Lewin (quoted in Marrow, 1969 )

With this epigram, the subtle problem of relating theory to practice, and thought to action, is reduced to a few words that hardly communicate the rich context of ideas which bore them. Today, this epigram evokes the dull surprise of a platitude, and is recited as almost a catechism answer to questions about the meaning and value social science theory. Of course we should theorize about persons' groups, organizations, even societies, so that we can make them better. This epigram offers a welcome idea, but what does it mean? And, is it true?

Socrates observed that "once a thing is put into writing, the composition, whatever it may be, drifts all over the place, getting into the hands not only of those who understand it, but equally of those who have no business with it" (quoted in Feyerabend, 1987 , p. I09). This paper presents a fresh examination of Lewin's epigram to see if in our hands it is treated properly, and if it deserves the faith we place in it. After a brief survey of the problem of relating theory and practice, the paper compares the two as types of knowledge - theory being the knowledge that explains things, and practice being the knowledge that get things done. Next, differences between these knowledge types are examined in order to determine precisely how they are related. Contrary to a literal interpretation of Lewin's epigram, these types are found to be logically incomensurable, such that it is impossible to apply one to the other or to translate between them. The paper then critiques three approaches which have been taken to the problem of relating theory to practice, including that taken by Lewin. The paper concludes with a re-examination of the practical value of theory, and proposes a revision of Lewin's epigram.' 
It seems we do not always need to know the theory behind our actions in order to perform them. Children master language before learning its theoretical grammar (indeed, they must know how to use language in order to learn from the teacher what its rules are). And, even when we have a theory, we may not be able to act. It is possible to know the rules of chess and not be able to play it well, or know what must be done to play the piano and still not be able to play it. There is skill involved in using chess rules and piano facts that is not contained in those rules or facts.

And so it is in social life. There too, the value of theory may be questioned. A business executive may know that it is important to delegate tasks, or involve subordinates in decision-making, and still not be able to do these things effectively. Or, a parent may see a child's need for discipline and not know how to instill it. It is one thing to know the rules or laws of social behavior, and another to act according to those rules or laws.

These problems become apparent to the social theorist when he or she tries to coordinate theoretical concepts with how things are experienced or performed in practice. Many theoretical concepts have no obvious counterparts in everyday life - e.g., the concept of force in theories of human motivation or macroeconomics, or the concept of structuration in theories of social action and structure. Other theoretical concepts exist only hypothetically - e.g., stereotypes in theories of interpersonal perception, or competition in theories of the firm.

This problem is particularly plain in connection with processes, which because of their dynamism resist theoretical explication. Perhaps this is why many social and behavioral theories traffic in verbs that point to outcomes of processes, not to the processes themselves (Sandelands \& Drazin, 1989). For example, the verb 'reinforce' in behavioral theory points to the fact that responses recur with reinforcing circumstances, but not to any process that is responsible. A process is hinted, but not specified. Other examples are the verbs 'choose' and 'select' which appear in economic and evolutionary theories of social structure. These verbs point to the fact that structures are adapted to their environments, but do not specify how this happens. Again there is an appearance of process, but an appearance only. Ryle (1949) called such verbs 'achievement verbs' because they retail achievements instead of the processes leading up to them. They contrast with 'task verbs' such as look, move, listen, and talk which refer to definite actions or events.

Problems of relating theory and practice are apparent also when moving in the opposite direction, from practical experience to explanations. Consider the difficulties of explaining how business executives lead others, manage information, solve problems, or launch a new business. These skills defy facile description or explanation, and seem to be learned only by doing. This problem 
is familiar to educators interested in helping executives manage organizations better. For example, Whetten and Cameron (1984) refer to it as a reason for writing a book about management skills:

The impetus for writing Developing Management Skills grew out of our frustration with teaching management courses following conventional methods. In our search for alternatives, we asked recent graduates to evaluate the organizational behavior and management curricula in terms of their experiences as managers. In general, these graduates criticized behavioral science courses for not teaching them job relevant skills. They were acutely aware of the challenges posed by "people problems" in their work, and they felt that their education had not prepared them for that component of their job.

At times, theory-based management courses seem positively counter-productive. Theories fracture practice into parts and divert attention from the whole which must be understood and mastered. This problem is noted by Michael Brown in a Wall Street fournal editorial about management training programs:

... If, as I suggest, most of these programs are good, why do I not become the supermanager of my aspirations? At various times I've learned how to approach my job as a total business system, how to quantify and measure everything, how to plan strategically, how to manage change, how to manage my time, how to get results by motivating others, and umpteen other proven approaches to successful management. . . . All this leaves me confused as hell. My management instincts have been watered down. I've now been conditioned to stop in the middle of some management activity and try to remember which techniques might apply. The different management techniques seem to meld into an anti-synergistic mixture, in which the sum is less than the totality of its parts.

Evidently then, theory and practice are different kinds of knowledge. Theory involves knowing that certain things follow from other things; such as that worker behavior depends on the expected value of alternative behaviors, or that social structure is a function of task and market forces. This is knowledge in the form of explanation. In contrast, practice involves knowing how to make certain things happen; such as how to motivate workers to be productive, or raise children, or calibrate social structure to pressing demands. This is knowledge in the form of understanding. As Ryle ( $1949: 54$ ) has pointed out, understanding and practice are exercises of the same trade - understanding a performance being an aspect of the competence to execute that performance.

\section{THE CONCEPTS OF EXPLANATION AND UNDERSTANDING}

\section{Explanation Defined}

Hempel and Oppenheim ( 1948 ) conceive of explanation as the application of reason to natural experience. A thing is explained (the explanandum) when it is shown to follow logically from statements about initial conditions and general laws (the explanans). Although explanations take several forms (e.g., causal, 
teleological, probabilistic), they can be compared according to their logical rigor; the best ones being those which adduce the explanandum by deduction. According to Taylor (1970), events are explained by their relation to universal generalizations. As an example, he shows how Boyle's Gas Law explains why the pressure of a gas $(\mathbf{x})$ increases when heated:

(1) Gas ( $x$ ) is in container (y), which is of fixed volume

Antecedent

Conditions

(2) Volume held constant, the pressure of a gas increases with increasing temperature
General

Law

Therefore:

(3) Pressure of gas ( $x$ ) in container ( $y)$ increases when heated

Fig. I: Explanation using Boyle's Law (fom Taylor, 1970)

This is an example of syllogistic reasoning. The explanandum must be true if the two premises of the explanans are true.

Unfortunately, social events rarely admit such straightforward explanation. Consider the following event described by Hempel and Oppenheim (1948):

In the fall of $194^{6}$, there occurred at the cotton exchanges of the United States a price drop which was so severe that the exchanges in New York, New Orleans and Chicago had to suspend their activities temporarily. In an attempt to explain this occurrence, newspapers traced it back to a large-scale speculator in New Orleans who had feared his holdings were too large and had therefore begun to liquidate his stocks; smaller speculators had then followed his example in a panic and had thus touched off the critical decline.

Following Hempel and Oppenheim, the event of the cotton market crash can be represented as a logical consequence of antecedent conditions and general laws. As antecedents there are the facts that the first speculator had large stocks of cotton, that there were smaller speculators with considerable holdings, that there existed the institution of the cotton exchanges, and so on. As general laws there are unstated but clearly implied laws of supply and demand and laws governing the behavior of individuals trying to preserve or improve their economic position. Patched together this way, the explanans explains the cotton market crash in the same way that the increase in gas pressure was explained above - as a logical deduction. The events of the crash are related to abstractions which show the crash to be reasonable - i.e., that it is something we can reason about. It does not show, however, how the crash occurred, which would require an explicit accounting of the complex of actions and events that were involved. Explanation speaks to the fact rather than the process of the crash.

How Explanations are Made. As indicated, explanations are made by a process of inductive generalization whereby events are analyzed into parts and 
generalized to abstract types related by universal laws. These types and laws are derived empirically, presumedly by induction from similarities and differences among events previously observed (although this last point is sometimes debated). The process is abstractive in the two-fold sense that it concentrates on shared as opposed to individuating details of events, and that its principal concepts are defined at the aggregate or group level (i.e., the abstract type). Its aim and result is to translate particularistic and immediately given perceptive experience into a simple few general concepts and principles.

The mechanics of the process can be illustrated by the example employing Boyle's law above (Figure 1). As noted, the behavior of a particular gas in a particular container is explained by the general law that gases confined to fixed volumes increase pressure when heated. To make this explanation requires that we $\mathrm{I}$ ) establish the abstract concepts of 'Gas' and 'Volume' and their relation in respect to temperature and pressure; 2) recognize that substance $(x)$ is an instance of a gas, and that container ( $y$ ) was an instance of a volume; and 3 ) see that what is true at the level of abstract concepts (gases and volumes) is true also at the level of particular events (substance $x$ and container $y$ ). To take these steps requires that we be able to abstract and reason correctly. Although not part of the explanation itself, these intellectual abilities are crucial to the process.

\section{Understanding Defined}

It is telltale about understanding that it seems not quite a noun and not quite a verb. As a noun, it suggests a thing that a person has or possesses ("He has a broad understanding of music", or "She can explain her actions, but she has no understanding of what they mean"). Commonly, it is regarded as a mental image or idea - akin to a motion-picture that can be replayed at will and from which observations can be made about what has happened and what will happen in the future.

However, as Wittgenstein (I 953) pointed out, this is a metaphorical way of talking that should not be confused with what actually goes on inside the person To have an understanding is not to have in mind an image or picture, or for that matter a symbolism of any kind. Rather, it is to be able to do things in regard to that phenomena - e.g., to perform it, comment upon it, draw a picture or diagram of it, or answer questions about it. As an ability, understanding is completely different from explanation. An explanation can be imparted, but an understanding can only be developed, and while this development is a gradual process, imparting is relatively sudden. It makes sense to ask at what moment something is explained, but not to ask at what moment it is understood (see Ryle, 1949:59). A good example of an understanding is the ability to use language. Understanding a language commonly means being able to say 
meaningful things and comprehend the sayings of others. It might also mean being able to read and write, or even being able to recite rules of grammar. Linguistic understanding is not a possession of facts, but an ability to use language effectively.

As a verb, understanding suggests a process (e.g., "He is coming to understand Kierkegaard", or "Don't just listen, understand what I am saying!"). However, this use of the word can be misleading. Understanding is not a true process that can be identified with a definite mental operation or activity. Rather, it corresponds to any process that exhibits an ability to do something. For example, a person "understands" chess by discerning its nuances, or by anticipating what players will do, or by playing it proficiently. These are all instances of understanding, and not separate from it. One does not first understand chess and on that basis play it. Understanding is not an occult process that goes on behind the scenes.

Understanding is allied closely with the verb 'to see'. Grammatically, these concepts are almost identical - e.g., people often talk about understanding in terms of seeing ("Oh, now I see"), or in more general terms of making sense ("Now it makes sense to me"). Understanding often involves visualization or other sense-making processes. This is why having an understanding often is described as being in possession of an "image" of some kind. This is why also achievements of scientific understanding often are associated with development of new tools for seeing - e.g., optical prostheses such as microscopes, telescopes, and bubble chambers; advances in computation, or new mathematics.

How Understanding Develops. Whereas explanation is made by a process of generalization, understanding develops by a process of particularization whereby diffuse actions or action tendencies are progressively narrowed and refined to produce expertise. And whereas explanation produces new abstract ideas or concepts, understanding produces nothing new, but gives play to certain existing actions and not others. The process is extractive rather than abstractive, behavioral rather than intellectual.

The growth and development of understanding is grasped most easily when it is manifest as an observable skill. Consider, for example, the complex skill to play a difficult piece of music on the piano. This skill cannot come any way other than by doing - by practicing the piece until its movements are all in place and second nature. In a short piece, this skill may come with practice of the entire piece. In a longer piece, this skill may come in stages - starting with mastery of parts followed by a process of assembly that makes the whole. Although this procedure superficially resembles the reductive logic of explanation, it is fundamentally different. Mastery of parts of a piano piece does not add up to mastery of the whole. Between the parts are transitions which, to be mastered, require that the piece be re-analyzed into new parts that encompass old transitions. This in turn defines new transitions and new problems of mastery. This suggests that the development of a complex skill may depend on many 
analyses of the whole - no single analysis being sufficient to produce the whole skill.

Understanding thus develops by direct and ongoing confrontation with practical problems of mastery which are often shifting and fluid. Roethlisberger ( 1977 ) describes the process as unitary and organic - a gradual and ongoing development, ever creative and new, and focussed always at the point of interaction. For him, as for us, this development could not be a result of reasoning, since that would imply a reduction of the unitary whole into parts and a logical progression from parts to whole. There is no reasoning process operating backstage, but only the developing skill itself. ${ }^{2}$ This is not to deny that thinking may play a part in the process, even a necessary one. However, where thinking enters, it is as a reminder of what has been learned already (especially of that which may have been learned only faintly or recently), and not as a basis or cause of what is yet to be learned. Thus, for example, in learning how to run an effective business meeting, thoughts had along the way, such as to "set out a clear and specific agenda", or to "make sure everyone is heard from", or to "watch out for potential conflicts!", are part of the developing skill. They recall past lessons and bring them into the present. Being mindful of what one is doing when acquiring or exercising a skill is simply one way of going about it.

\section{RELATION BETWEEN EXPLANATION AND UNDERSTANDING}

The idea that there is nothing so practical as a good theory is commonly taken to mean that explanation can be translated into understanding. Presumedly the logical structure of explanation reveals what practitioners can do to bring about desired effects. In what follows, five arguments are presented to point out some of the difficulties with this view. These arguments suggest that understanding cannot follow from explanation, but to the contrary, that it must be prior to it. They suggest more generally that all knowledge, including that of explanation, begins with and presupposes understanding. Based on these arguments, implications for conceptualizing the relationship between theory and practice are discussed.

\section{The Arguments}

Argument 1: Wordsworth, Emerson and the Unity of Nature. Wordsworth was an astute critic of the scientific explanations of his day. This is from his poem, The Prelude:

Science appears but what in truth she is, Not as our glory and our absolute boast, But as a succedaneum, and a prop To our infirmity. No officious slave 
Art thou of that false secondary power

By which we multiply distinctions, then

Deem our puny boundaries are things

That we perceive and not that we have made.

To thee, unbinded by these formal arts.

The unity of all hath been revealed.

This idea about science is captured also in his famous epigram: "We murder to dissect". Wordsworth's consistent theme is that the important facts of nature elude explanation. He objects to the idea that phenomena can be understood by setting forth initial conditions and lawful regularities. In his view, no sensible reduction of the whole into parts is possible. He finds in each of the parts, always, a "brooding presence of the whole".

A similar argument and sentiment is voiced by Emerson:

Empirical science is apt to cloud the sight, and by the very knowledge of functions and processes to bereave the student of the manly contemplation of the whole. The savant becomes unpoetic. But the best read naturalist who lends an entire and devout attention to truth, will see that there remains much to learn of his relation to the world, and that it is not to be learned by any addition or subtraction or other comparison of known quantities, but is arrived at by untaught sallies of the spirit, by a continual self-recovery, and by entire humility. He will perceive that there are far more excellent qualities in the student than preciseness and infallibility; that a guess is often more fruitful than an indisputable affirmation, and that a dream may let us deeper into the secret of nature than a hundred concerted experiments.

Thus Wordsworth and Emerson doubt the very idea that understanding can be achieved through explanation. They believe that analysis distorts reality by obliterating its unity; by multiplying puny distinctions and pretending them real; and by denying the student's native powers of observation and understanding. And, because they cannot recognize the real in scientific explanations, they wonder what sort of understanding is gotten by them.

Argument 2: Hume, Quine and Philosophical Skepticism. The idea that explanation leads to understanding is diminished also by investigations of the limits of explanation. This is the lesson in Hume's (1748/1955) skepticism of rational science. Hume wanted to know the rational basis for knowledge about relationships; and in particular, the relationship of causality. After an earnest search, he found no a priori or a posteriori basis for inferring effects from causes. He wrote that "even after we have experience of the operations of cause and effect, our conclusions from that experience are not founded on reasoning." 3 Causation cannot be explained, it must simply be understood. Causes do not have reasons.

Hume's analysis can be generalized to all forms of logical explanation including the syllogism. The syllogism equally cannot be rationalized or explained. Its truth is similarly self-evident, and similarly 'just understood'. Today, many philosophers join Hume in denying that explanations are 
established either by induction from experience (synthetic statements), or by logical analysis (analytic statements). Quine (1953:42-43), for example, has argued that the truth of every proposition (including those of the logical calculus) is contingent and depends upon an essentially intuitive appraisal of the whole system in which it functions. The system must already be understood, before it can be explained. Rather than leading the parade and showing the way to understanding, explanation follows behind, sweeping up the refuse into neat piles which make for easy pick-up, but in their very organization, leave a misleading trail of what went before.

Argument 3: Wittgenstein and the Idea of Seeing. Then there is all the trouble Wittgenstein started. He showed that explanations (and descriptions in general) are not self-sufficient or absolute, but require an observer to fix their reference and meaning. Far from being accomplished facts, set once and for all, they lead a tenuous and often ephemeral life at the mercy of understanding observers.

This is most easily demonstrated with pictures. Figure $2 \mathrm{a}$ is from Wittgenstein ( $1953: 194$ ). This figure can be seen either as a rabbit or as a duck, with the protruding portion seen either as ears or as a bill. Figure $2 b$ is similarly ambiguous and can be see either as an old woman facing sideways, or as a young woman facing away and to the right. Figure $2 \mathrm{c}$ is called the Necker Cube. Its ambiguity concerns which face is at the front.

In all three examples, a single set of parts can be seen in multiple ways. Their ambiguity develops not from the parts themselves, but from the act of seeing them. To be sure, Figure $2 a$ is abstract and stylized, and perhaps could be said to be inherently ambiguous. Yet, this is not true of Figure $2 \mathrm{~b}$ which is more definite and articulated. In Figure $2 c$, the tension between ways of seeing the figure is acute - first one assumes prominence, then the other. Wittgenstein and others (e.g., Hanson, r 969 ) use figures such as these to show that formal descriptions presuppose an ability to see, and that what is seen depends on how this ability is exercised.

In the same way, what is taken to be the explanandum in an explanation depends on how the explanans is interpreted. To return to the example of the cotton market crash, the same explanans can be used to explain the drop in market price or the increase of sales volume or the despair of the small investor or the swelled pride of the New Orleans fat cat. $\Lambda$ single explanans can generate multiple explanandums. Which it will be depends on how the observer chooses to understand the situation.

The role that prior understanding plays in explanation is often hard to detect because it is deeply embedded and rarely questioned. To return to the example of the rabbit/duck, this role is obvious only if we compare the views of, say, a vegetable farmer interested to find out who has been eating the lettuce, and a duck hunter looking for something to shoot at. Each knows for certain what they see. Curiously, we who are unprepared are not so sure. 


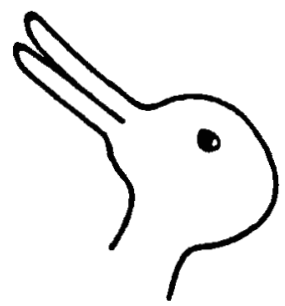

Fig. 2a: Willgenstein's Rabbit/Duck

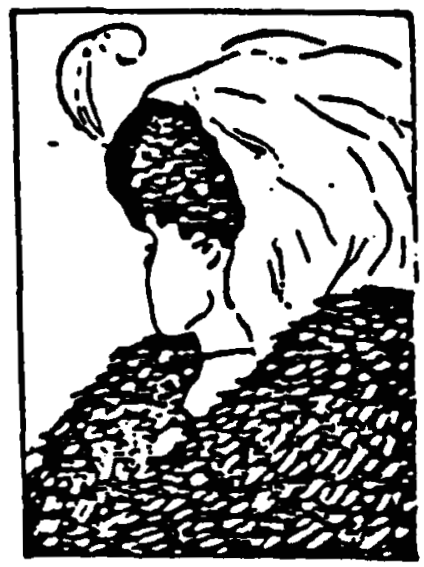

Fig. 2b: Toung Woman/Old Woman

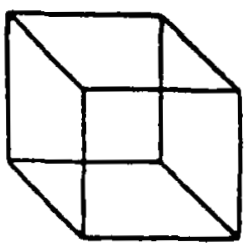

Fig. 2c: Necker Cube

Argument 4: The Argument From Psychology. The idea that explanation leads to understanding is dubious also as a proposition about psychology. It implies that the ability to see or do things - i.e., to understand - can develop from rational analysis. But this is belied by certain facts of perception.

Figure 3 a [from Palmer, 1975] is obviously a face. If asked how we know this, we say because it has two eyes, a nose and a mouth. Now consider Figure $3 b$. If asked what the first object is, we are apt to say we don't know, or that it is a semicircle, or an arc of $\mathrm{I} 80$ degrees. If asked about the second object, we are likely to say it is a triangle, or perhaps a pyramid. And so with the third, which we would probably call a circle. We do not see a mouth, nose or eye. Rather, we see abstract, geometric figures. 


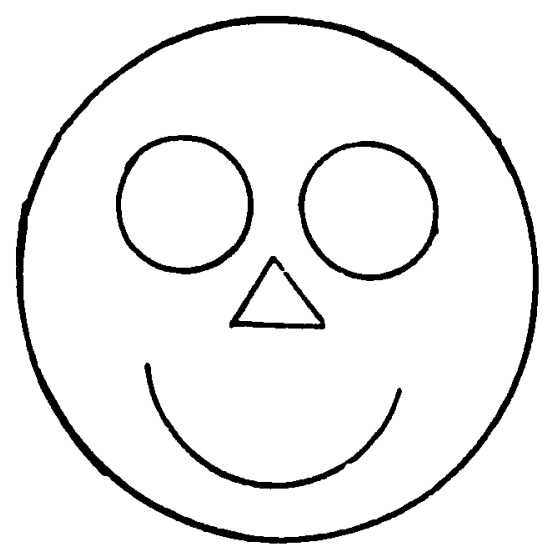

Fig. 3a:
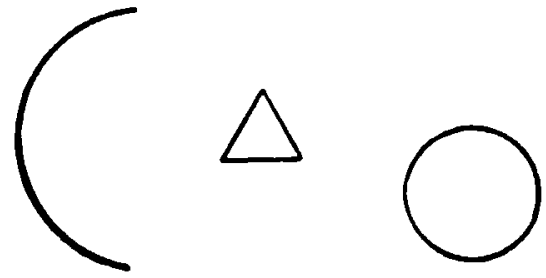

Fig. $3^{b}$ :

Notice what has happened. We say that the whole is known by the parts, and at the same time, that the parts are known by their place in the whole. This is called the 'parsing paradox'. It arises because understanding (in this case, our. ability to see the face) is mistakenly assumed to abide by the same rational logic as explanation, as if it were possible to reason oneself into understanding. ${ }^{4}$ As Searle ( 1984 ) has pointed out, the failure to see this error has led to misguided theory. It is behind a family of problems concerning how psychological qualities such as meaning or feeling are derived from logical structures such as linguistic grammars, rational models of perception, or digital computers.

In retrospect, this paradox is unsurprising. It recapitulates the problem posed by Wordsworth, Emerson, Hume and Quine. Recall Wordsworth's point that it is impossible to talk about parts independently of the whole-there is in each of the parts, always, a brooding presence of the whole. Recall also Hume's point that relations such as between whole and part cannnot be rationally justified. It seems that problems left unresolved by the philosophy of knowledge (epistemology) always find a way to torment psychology. ${ }^{5}$ 
Argument 5: The Evidence of Language. Finally, there is the wisdom of language; which by its structure and modes of operation marks humankind's progress in the struggle for understandng. Language, too, reveals why explanation cannot lead to understanding, and indeed why understanding is necessary for explanation.

Explanation demands precision from language. Words must be used in strict denotative ways so that the explanandum can be logically deduced from facts set forth in the explanans. In contrast, understanding demands evocativeness from language. Words must be used in looser, connotative ways if a person is to see or enact the phenomena in question. This is accomplished linguistically by exemplification, through figurative devices such as simile and metaphor. Figurative language invites the reader to go beyond the words and to create his/ her own image of the process, and in this way understand how it happens.

The reason why explanation cannot lead to understanding is because its words denote rather than evoke. This keeps the reader from becoming actively and imaginatively involved in the process and thereby interferes with his/her grasp of what is going on. This is a large part of the reason why literal, discursive language fares so poorly in conveying natural events and processes. According to Arnheim (1966:23I), literal language has particular difficulty with interaction:

... the task of describing interaction discursively is insoluble in principle. Conceptual theory can predict the outcome of interaction, but it cannot adequately describe the process itself, since by its very nature it can account only for linear connections among entities.

In practice, of course, every explanation is evocative to one degree or another, if for no other reason than that some terms are imprecise and require interpretation by the reader. As Hume showed, this is the case generally for words that denote relations. Such words cannot be fully explicated but must simply be understood. Thus, figurative language almost inevitably makes its way into scientific writing, despite being imprecise. These incursions are approved by those who identify science with understanding (e.g., see Morgan, I 983), and reproved by those who identify science with explanation (e.g., see Pinder \& Bourgeois, 1982).

Tension between the language requirements of explanation and understanding is sometimes felt when the balance between them is upset (Quine, I 981). Excesses one way or the other - in the direction of liberalized or of restricted language - invite protest and calls for reform. The complaint these days is that scientific discourse is too dry, too esoteric, and too full of jargon. There is nostalgia for the rich and evocative language of yesteryear - such as written by James, Russell, and even Einstein. This is not mere sentimentality; but reflects a need for understanding, a need to "see" what scientists are talking about. $^{6}$ 
Taken together, these arguments raise serious questions about the idea that explanation can be translated into understanding, and by implication, about the idea that theory can be translated into practice. Explanation appears not as the vanguard of understanding, but as the occupying force left behind. It is derivative and secondary, founded on abstract logical principles, linked to understanding by a paradoxical psychological process, and fabricated of literal language that cannot reproduce the experiences from whence it came. A relationship between explanation and understanding is suggested, but it is all the other way. Understanding furnishes explanation its basic concepts and logic, and moreover the background necessary to make sense of what it says. Explanation presents formally and incompletely what is already understood.

Save perhaps for its juxtaposition of arguments, the exposition so far offers little that is new. As to the relationship between explanation and understanding, it traces a well-worn path that dates at least from Aristotle (who seems to have walked them all) and continues to the present day. In contemporary social science, its wayfarers include Polyani ( 1967 ), who makes an essentially similar distinction between explicit and tacit knowledge, and, likewise, Roethlisberger (1977), who makes a distinction between knowledge (clinical or analytical) and skills. For Polyani, tacit knowledge is that which cannot be spoken and which comes before that which can be spoken. For Roethlisberger, all genuine knowledge, from clinical description to rigorous explanation, rests upon and presupposes intuitive understanding or skill. Thus, on this score, the present paper can be seen as keeping alive an idea and conversation that has been going on for some time.

Finally, and before proceeding, one more distinction must be made. This is between knowledge types as defined (i.e., explanation and understanding) and the understanding which makes these knowledge types possible. The latter refers to abilities which a person must possess in order to explain or understand. These abilities constitute a second order of understanding (which we might call secondary or meta-level understanding). This is a distinction of logical type which, if we do not keep it in mind, can lead to misspecification of the relationship between explanation and understanding, and parri passu, to misspecification of the relationship between theory and practice. For example, we do not want to confuse the fact that both explanation and understanding presuppose a kind of meta-level understanding, with the unimplied idea that they are logically connected. Similarity at one logical level implies nothing about similarity at other logical levels.

\section{APPROACHES TO THE PROBLEM}

The foregoing arguments suggest that to argue that theory can be applied to practice, a way must be found to translate between them. Somehow the differences in logical characteristics noted above must be surmounted. 
Below, three basic approaches to this problem are discussed and critiqued. One approach, that taken by Kurt Lewin, unites theory and practice within a common epistemology. It assumes that if theory and practice are made the same way, then they must be related. A second approach, taken by action theorists such as Argyris and Schon (1974), removes the differences between theory and practice by reconceptualizing practice as a kind of theory. It conceives practice as having the same logical structure as theory. Finally, a third approach, taken by philosophers of social science such as Brown ( 1976 ) and Morgan ( 1986 ), removes the differences between theory and practice in the opposite way, by reconceptualizing theory as a kind of practice. It conceives theory, not as explanation, but as metaphor. Theory becomes a kind of action taken in the interest of understanding. Although none of these approaches bridges the logical gulf between theory and practice (which is impossible), each in its own way throws additional light on the problem of relating the two.

\section{Kurt Lewin on Theory and Practice}

For his biography of Kurt Lewin, Alfred Marrow chose the apt title: The Practical Theorist. Certainly, Lewin must be counted among those who have worked hardest to bring theory and practice together. As Marrow describes, many of Lewin's theoretical ideas arose in connection with work on practical problems, such as those of child development and health, leadership, factory production, prejudice, social conflict, mass communication, and group dynamics. His ideas of life space, expectations, intentions, and motives, have proven their value time and again for describing practically important individual and social behaviors.

However, Lewin's own conviction about the practical value of theory probably had more to do with his epistemology, than with his focus on practical problems. He approached his science as a practitioner - with a view to making things happen. The key was experimentation. To Lewin, a concept became interesting only when it could be used to do something, when it could be manipulated and experimented with. This, he argued, requires a familiarity and knowledge of the concept that goes way beyond abstract appreciation. It requires the scientist to take all relevant factors into account, just like a practitioner. To be effective, both must be aware of the entire psychological field (Lewin, 1947). Moreover, in the process of taking action, the scientist develops a practitioner's knack for getting things done, for making a difference. According to Lewin, the methods of developing sound theory and practice are the same, and thus it is natural to assert a relation between them. Good theories are practical because they are built through practice.

Although Lewin's view of theory and practice is compelling, it poses two difficulties. Most important, it is founded upon the error of logical typing noted 
above. As pointed out above, similarities in the understandings which produce theory and practice imply nothing about similarities between the theory and practice produced. This confuses processes of knowing with things known. It is not enough that the theorist and practitioner act in similar ways; still they are making different things, and still it is not possible to translate between those things.

Second, although there are similarities between the methods of the theorist and practitioner, there are also basic differences which result from the fact that these methods are aimed differently - the former to make inferences, the latter to take action. In particular, al though both try to take all relevant factors into account, they do so in different ways. The theorist confronts situations conceptually, in terms of abstract concepts which can be arranged in a logical framework of antecedent conditions and general empirical laws. He/she takes all relevant factors into account by enumerating their impacts on the application and extent of general laws. In contrast, the practitioner approaches situations behaviorally, in terms of actions intended to accomplish certain objectives. He/she takes all relevant factors into account by adapting action to the demands they make on this process. Whereas theory is based on conceptual analysis of situations, practice is based on an aconceptual process of behavioral refinement through winnowing behaviors and correcting errors. The two logics are different, and for this reason so are the knowledges they create. ${ }^{7}$

The differences between theory and practice thus are fundamental and not resolved by actionable operationalizations or experimental methods. Each relates to its subject in its own way; theory as a conceptual abstraction from experience, a generalization from particulars; and practice as an extraction of behavior, a singling out of particulars. Between them is an unbridgeable gulf. Theory is of the mind, practice is of the body, and the problem of relating them recapitulates the problem of relating mind and body. Whereas it is one thing to assert that the mental activity of theory affects the physical activity of practice, it is quite another to say how this happens (see, e.g., Searle, I984). This problem of moving between the two, between mind and body and theory and practice, has been the main philosophical problem since Descartes and remains unsolved.

\section{Action Theory}

Lewin's practical psychology finds a contemporary voice in theories of action. These theories attempt to close, or at least narrow, the gap between theory and action by making action their subject. Examples are theories of how people use language (e.g., Chomsky, 1972), perceive others (e.g., Heider, I958), think about tasks (e.g., Sandelands, I987), manage business organizations (e.g., Argyris and Schon I974), or make sense of collective environments (e.g. Weick, 
1969). Unlike ordinary theories which refer to persons, action theories are of persons. They retail psychological structures of the actor which allegedly determine his/her behavior.

Action theories are generally constructed on the same hypotheticaldeductive platform as ordinary explanatory theories. Ideas for action are deduced from general laws and antecedent conditions which are codified in the form of rules or performance programs. The main difference between explanatory and action theories is that whereas the explanans and explanandum of the former refer to manifest events and actions, those of the latter refer to ideas about events and actions. Argyris and Schon (1974, p. 5) describe action theory as follows:

For example we may attribute to a counselor a theory about the way to handle disruptive students: "It is necessary first to speak to them in their own language and to make it clear that you understand them, then to state the limits of what you will tolerate from them, and only then to try to find out what's bothering them." All such theories of action have the same form: in situation S, if you want to achieve consequence $\mathrm{C}$, do $\mathrm{A}$...

Unfortunately for our view of them, action theories are characteristically unconscious. This is illustrated by theories of language grammar which contend that people unmindfully obey certain rules when producing or understanding speech acts. According to Chomsky ( 1972 ), language users need not be aware of these rules, and indeed would probably find it a liability to think about them (for then they might get confused about which rule they should follow, in what situations, and when). Being unconscious, action theories cannot be studied directly, but must be inferred from observed behavior. As in the example of language grammars, propositions or rules for behavior, as well as the conditions for applying them, must be gleaned from regularities observed across behaviors and across situations. As a procedure, one works backwards from such regularities to infer rules which explain them.

Although action theory offers a compelling explanation of practice, from which action can be accurately predicted given knowledge of its circumstances, it does not describe practice itself. From it, one can logically deduce that a particular action will take place, but one cannot say how that action will take place. As an instance of explanatory theory, action theory comes no closer to practice than any other kind of explanatory theory. To be sure, by moving inside the head of the practitioner, and by focusing directly on his/her actions, it does seem more practical than theories which operate at greater remove from the practitioner. But, in taking this position, it does not solve the problem of relating theory to practice; it only makes it harder to see. The untraversable chasm between theory and practice reappears as soon as we focus on the process by which action theory determines practice. This can be seen in Argyris and Schon's (1974, pp. 12-14) description of the process of learning to use a skill: 
Let us consider the skill of bicycle riding. Suppose that we put the entire program into a student's hands and that he studies the program so that he can repeat it and can state what the program says to do in various circumstances. This ability to repeat the program does not constitute learning the skill for three reasons. I) There is an information gap between the program and the concrete performance of riding a bicycle; that is, the program never gives a complete description of the concrete performance.... 2) Riding a bicycle requires smooth, uninterrupted sequences of responses. If we interrupt this flow of activity by attending to the particulars of what we are doing or by looping back through the explicit program we may fall off the bicycle. This is true not merely because of considerations of timing (the learner must compensate for an imbalance immediately, not a few seconds later) but because these sequences depend for their performance on Gestalt qualities that we lose if we attend to the particulars of the explicit program... 3) Some of the performances indicated by the program may require changes in sensory competence, muscular strength, physical dexterity, or feeling, none of which is achieved through learning the program for riding a bicycle (p. 13 ).

This description shows clearly that between action theory and practice is the same wide gulf as between explanation and understanding. Having an action theory or program is different from being able to do the thing to which that theory or program refers and purports to explain.

Nevertheless, Argyris and Schon argue that action theories are necessary for the development of sound practice. They insist that even in the example of riding a bike, the program must be learned in order to master the practice. Competent practice, they argue, consists of knowing both its underlying program and knowing how to internalize that program so that it is unnecessary to refer to it explicitly during practice. Skill arises when knowledge of the program is made tacit. But this raises certain other logical difficulties. First, by proposing that action theory is internalized as part of practice, it calls attention to another skilled activity (of internalization), which requires another action theory to explain. If we then ask, as the logic of this argument requires we must, how this superordinate action theory is internalized, we come to yet another instance of skilled activity (of internalization of the ability to internalize), and yet another theory of action and so on in infinite regress. This suggests that action theory can never be complete and that it can never quite be internalized. Second, if the process of internalizing action theory changes it into a skill, it is meaningless, if not contradictory, to assert that skill is explained by action theory. The tacit knowledge into which action theory is changed is what the theory was originally invoked to explain (and unacceptably, as Argyris and Schon point out).

Another view of these issues is given by the idea of 'rule following'. As Searle ( 1984 ) has pointed out, people do not follow rules in the way action theories suggest. In fact, they do not literally "follow" them at all. Being unconscious, these rules cannot be followed, at least not in the same way as we might follow the directions given by a map, or a recipe in a cookbook. There can be no mindful checking of actions against rules or against intended consequences (this checking being the sort of activity we identify with 'following rules'). Instead, 
the rules of action theory must be seen as metaphorical, and so too any following of them that might be said to take place. Action theories describe what would happen if people were to follow certain rules (assuming that they are able and willing). Thus, if people were to follow the rules of Chomsky's transformational grammar, they would produce a great number of acceptable english sentences (and some unacceptable ones too). This truly impressive generativity of the grammar does not, however, make it any less metaphorical. Still it is a rationalization of a process that it does not literally describe. How people actually are able to use language is beyond logical grammars to describe.

At a broader level, we see that action theory does not solve the problem of relating theory and practice, but only moves it to a new location. What was once a logical problem for us to solve, is made into a psychological problem for a homunculus to solve. Practice becomes a kind of computer program which the mind somehow relates to action. We are left not only with the original problem of explaining how theory relates to practice (which is not solved by being moved into the head), but, in addition, a new problem of explaining how action theory relates to other forms of explanatory theory. How, for example, does the physician's theory of action relate to theories of anatomy and physiology, or the business executive's theory of action to social science theories of complex organizations?

\section{Theory as Practice}

Finally, whereas action theory attempts to close the gap between theory and practice by making practice more theoretical, it is possible also to move in the other direction, by making theory more like practice. A regime of this kind can be read into recent writings, such as by Brown (1976) and Morgan (1986), which emphasize the metaphoric, as opposed to hypothetical-deductive, quality of theory. According to Brown (1976: p. I85), theory as metaphor functions "neither to copy reality nor to be an unbounded product of the romantic imagination. Rather, it provides a new way of understanding that which we already know." As opposed to static structures handed-down by the theorist and simply received by the reader, theory is conceived more dynamically as a kind of practice unto itself. Theory as metaphor invites the reader to play along to think for him/herself, to fill in details and make connections. So construed, theory is no longer logically opposed to other forms of practice, but is joined with them as an example of working knowledge which can be incorporated within a common action framework (see also, Susman \& Evered, 1978).

However, by regarding theory as metaphor we do not change the logical character of its relationship to practice. No matter how we choose to think about it, whether literally or figuratively, it remains theory. It cannot thereby 
be made any less an arrangement of concepts (or verbal tokens); nor any less incomensurable with practice, which was we have seen, is not a conceptual structure.

Again, we find that the maneuver of viewing theory and practice as alike does not solve the problem of relating them. And again, this conceptual gerrymandering produces two problems instead of the original one. First, although it suggests similarities between theory and practice, it does not establish a relationship between them. Although thinking theoretically, whether directed by metaphor or formal logic, is a kind of practice, it is still different from taking action - seemingly no more like it than dreaming about baseball is like playing it. They are just different activities. Second, this redistricting sets up a "new" problem of relating the concepts of theory as metaphor and as logical explanation. Actually, this is none other than a restatement of the original problem of relating explanation and understanding, which remains unanswered. Here again, the attempt to by-pass the problem of relating theory to practice ends up recapitulating it. The problem is moved but not removed.

\section{THEORY AND PRACTICE RECONSIDERED}

The discussion thus far has been aimed to show that explanatory theory and practical understanding differ in essential and insurmountable ways. They are different kinds of knowledge and arise from different interests and sensitivities. This perhaps is why the world seems divided between the two - between theories and practices, and between people interested in one or the other (e.g., between academics and practitioners, staff and line, visionaries and those who sweat the grubby details). This perhaps is also the grain of truth behind the familiar jibes that good theorists don't make good practitioners (i.e., "if you're so smart, why aren't you rich?"), and that good practitioners don't make good theorists ("If you're so rich, why aren't you smart?"). Were theory and practice more similar, we might expect more synergy between them.

If the logical distinction between theory and practice is genuine, it ought not be ignored or abandoned, especially if it cannot be surmounted. To the contrary, the distinction should be kept firmly in mind in order to prevent confusion. Thus, we should be grateful to hear theorists complain that practice is ill-defined, messy, and beyond reason; and to hear practitioners complain that theories are over-defined, sterile, and not actionable. Such complaints remind us of their disparate goals, and of our limitations in bringing them together.

\section{The Practical Value of Theory}

All of which begs a question (some would say it is the question) that has been frowning on these proceedings from the start, namely: if theory and practice are 
not related, then what leads us to think they are? Surely practitioners are not trying to deceive us when they profess to use theories. And, who could doubt theorists when they point with pride to the various technological advances that theories have brought, such as labor-saving machines, life-saving drugs, and regrettably, life-threatening munitions? Behind these testimonials, and the common sense they affirm, are familiar ideas about knowledge being power, and about theories being the tools which mediate and express this power. These are textbook ideas (see Beyer \& Trice, r 982 ) that give voice to the common belief that theories are useful and alike in functioning to other kinds of tools such as jackhammers, electric shavers, and personal computers. In the face of this, one feels more than a little silly denying (and so plumply too) the value of theory for practice. To be at odds with common sense is no place to be.

Nevertheless, the arguments of this paper clearly indicate that theories could not be tools because they are incomensurable with practice and cannot be translated into it. Whereas tools aid or enhance practice - as a wrench makes it easier to fasten or loosen bolts - theories stand apart from practice, and if they refer to it at all (as in Action theory), they do so only as an abstraction in the mind of the practitioner. Tools are of practice and are invented and evolve according to its necessities (their form follows function). Theories are no better than about practice and are invented and evolve according to conceptual necessities, rather than practical ones. Theories are shaped by the need to bring new observations or insights into a coherent rational framework (their form is unrelated to function). And finally, even if it were possible to conceive of theories as tools, their practical value would not be guaranteed. They require skill to be used. As any person who is not handy with tools knows, having them is not the same as being able to use them effectively. It is not the tool that is useful, but the tool as used by a capable practitioner.

However, it is possible to reconcile our remorseless logic with common sense by regarding the practical or tool value of theory, not as a logical characteristic, but as an ascribed characteristic. Even if theory cannot literally be practiced, there may be occasions when it is nevertheless 'practical'. Of these, the most important and compelling is when contact with theory calls to mind actions or action tendencies which otherwise would have gone unnoticed. In the extractive winnowing process of understanding, this can result in development of new skills or sensitivities. Here, theory enters into practice in something like the way art enters into experience. Just as art consists of an arrangement of materials (e.g., colors, shapes, sounds) which can (but need not) call to mind certain impulses and feelings in beholders, so too theory consists of an arrangement of ideas (e.g., concepts, propositions) which can (but need not) call to mind certain actions and feelings in practitioners. And, just as contact with art may bring out new ways of seeing or feeling, so too contact with theory may bring out new ways of practice. 
That we sometimes act differently for having been exposed to theory is beyond question. In calling attention to certain facts and not others, theory may, in the self-conscious and reflective reader, also call attention to actions that refer to those facts. In the ongoing and unfolding process of practice, where action tendencies interact and compound, even a minor change in emphasis may ramify, trip off new chains of action, and thereby alter the course of practice. This process is illustrated nicely by MacIntyre's ( 1985 ) description of how Freud's idea of the all-pervading influence of unconscious motives has entered into and changed the course of at least some social behavior in Western society. A powerful implication of this idea, he notes, is that behavior cannot be taken at face value, but must be interpreted in light of unconscious urges and impulses. He then asks what difference it has made to have this idea in the air, constantly calling attention to the "problem" of interpreting behavior:

A first consequence is that it becomes much more difficult to take the notion of an authoritative utterance seriously. If we treat such utterances as to-be-psychologically-decoded expressions of the utterer's personality, then we become unable to listen to what fathers say to children, headmasters or headmistresses to pupils, priests and ministers to congregations, presidents to the nation, with the kind of deference to the utterance itself which was once socially prescribed and desired (p. 9oo).

\section{Further,}

... the makers of authoritative utterances ... are apt to experience an embarrassing ambiguity and uncertainty in their relationship to their own utterance. How can they straightforwardly mean what they say when the overinterpretative mode has divorced manifest saying from latent meaning? And so we get the characteristic recent and new social performances of the systematically embarrassed father, the embarrassed priest, the embarrassed professor, and the variety of devices for fending off that embarrassment (p. goo).

\section{And finally,}

... the concept of understanding which accompanies the overinterpretative mode is one in which to understand the other is to perceive in him or her more and other than he or she perceives and acknowledges. The project of understanding comes to involve discrediting the surfaces appearances. But our surface appearances - what we ourselves take ourselves to be and present ourselves as - are necessarily very clear to us all, and thus understanding is now often enough experienced by its objects as an act of aggression. If I tell you that I am going to understand you, I now threaten you in a way that is culturally new. Hence it has become important in a new way to not be understood. Opacity has become a more valuable quality than ever before (p. gor).

Although perhaps overdrawn, this illustration of the impact of Freudian psychology highlights three key features of the way theory enters into practice. One is its crude and unreflective manner. Here it is not psychodynamic theory itself that is featured, but only the idea of unconscious motives; which as we have seen preys a constant doubt about surface appearances. In its light, nothing is simple; every act, large and small, is subject to interpretation. To take the idea 
seriously is thereafter to see human action in a completely different way. A second feature highlighted is that theory draws attention to actions or tendencies that are already part of the practitioner's repertoire, all be they perhaps dormant or diminished. The idea of unconscious motivation was familiar before Freud, and was at least a small part of the common sense of behavior interpretation. Freud's significant contribution was to put the idea center stage, where it could not be ignored, and where its shadow would darken our view of even consciously undertaken actions. This suggests that theory, like art, cannot show or teach us anything that we do not already know. Thus, the expert practitioner, not the novice, is most likely to be moved by contact with theory. By bringing more to the confrontation, he/she is able to take more from it. The novice, who does not yet possess the full range of sensitivities and skills needed for practice, is likely to find theory more impoverished in meaning and implication. Finally, a third feature highlighted is that ascriptions of practical value depend on the difference a theory makes, and thus are ascertainable only after the fact. In the case of Freudian theory, this difference has been to complicate social life, at least among those people for whom the idea of unconscious motives is salient and important. This difference, which could be either helpful or injurious, is not given or set by the theory, but by how practitioners act in light of ideas that it calls to mind. More so than those of others, Freud's penetrating ideas about the human psyche were received by a culture that was ready to resonate with them.

Certainly Freud did not anticipate or intend the social paralysis that has occurred among persons sensitive to his ideas, but he did anticipate and intend other more salubrious developments (e.g. of psychotherapy, projective testing, dream analysis). Indeed, our sense that theory can be practical is most strongly supported by instances where, in the company of theory, practice develops in hoped-for ways. This is often the case in training where instructors or how-to manuals offer learners theories or frameworks which call attention to actions that should or should not be repeated. Where it is effective, training highlights actions related to successful performance, and by so doing increases the likelihood they will survive the winnowing process of developing practice. Thus, for example, people who are notoriously inept at reasoning with probabilities can be trained, at least for a time, to reason correctly by forcibly 'reminding' them of the ways of Bayesian analysis and motivating them to use them (see Tverksy \& Kahneman, 1974).

Further examples where theory figures in the development of practice are actions taken in light of theoretically-derived ideas about the future. Because the human mind can see only so far into a complex and uncertain future, it is often necessary to rely on formalized procedures (e.g., of calculation or simulation) to guess what the future will hold - as, for example, in setting economic policy based on forecasts, or aiming spacecraft at the moon based on projections of relative positions (in the latter case hopeful that these procedures 
are more trustworthy than in the former!). Again, theory enters practice the same way. It offers an idea (e.g. a deduction about the future state of the economy or a calculation of positions in space), which in the ongoing matrix of practice calls attention to certain actions and not others (e.g. of policy or piloting), and in this way affects how practice unfolds. ${ }^{8}$

Returning to the comparison of theory to art, we see also how it could explain how we are taken in by the idea that theory guides practice, despite our sure knowledge to the contrary. This resembles the confusion often noted between art objects and experiences of them. Confusion occurs when these experiences, which belong exclusively to the beholder, are "read into" the objects or mistakenly attributed to them. The illusion can be quite compelling. We see a painting as being angry or causing despair, or a musical piece as joyful or giving us a lift. However, what the art work "presents" and the beholder "experiences" are completely different, they are concepts of different kinds and origins. Art does not cause beholder experience, which rather is constituted by impulses and feelings that are present already in the beholder; existing, as it were, unexpressed. In the same way, practices, which likewise are present already in the practitioner, may be confused with, or "read into", theories in whose company they were founded. Thus, a business executive may confuse administrative practices with theories of administration, or a linguist may confuse speaking practices with language grammars, in both instances assuming that the latter was responsible for the former. Ironically this sort of misattribution may be most pronounced among expert practitioners who, because of their superior practical understanding and ability to appreciate theories, have more opportunities to make it. This suggests that the expert practioner, whose opinion about practice we should most respect and trust, may be least able to specify correctly how that practice is related to theory.

It is well to notice too that even if theory does not play the evocative role suggested by comparing it to art, and even if it does not actually enter into practice, nevertheless it may appear to us as doing so simply because it grows up in the same neighborhood as practice. A person involved and committed enough to build a theory about something is likely to develop a practical understanding of it as well. As argued above in the case of Kurt Lewin, the process of scientific inquiry, and especially experimentation, bear upon both theory and practice. The experimenting scientist gets to be good at making things happen. Thus, even if theory and practice cannot be joined, they still can keep one another company.

Finally, no matter what the actual relation between theory and practice, we may still find it worthwhile to believe that theory is practical. Well-founded or not, this belief can inspire the confidence necessary to take action, especially in difficult or ambiguous situations, and this can promote the learning necessary for improved practice. Understanding comes by doing, no matter how motivated or brought about, and often it is better to take even the wrong action, 
rather than none at all. Additionally, this belief gives hope to a more general and basic need. Human society depends for its survival on the transmission of practical understanding (e.g., of agriculture, engineering, medicine, law, defense) from member to member, and from generation to generation. Where in the past this understanding was conveyed only slowly and gradually by hardwon apprenticeship (i.e., through practice itself), it would be a substantial advance to codify it in the form of theory, which could be written down and communicated much more easily. This might speed its dissemination to wider parts of society and safeguard society from its possible loss. Such gains could never be made, except on the wishful assumption that theories can be practical. ${ }^{9}$

\section{Lewin's Epigram Revisited}

Returning finally to Kurt Lewin's epigram that there is nothing so practical as a good theory, we see that it admits no simple interpretation, and certainly not the literal one too often given or implied, i.e., that theory can be applied to practice and used to guide it. As this paper has attempted to show, this is impossible because theory and practice are logically incomensurable, and consequently, not intertranslatable.

Nevertheless, we may be able to justify the epigram by thinking about the practical value of theory, not as a logical characteristic, but as an ascribed characteristic that is justifed more or less, depending on the occasion. Practice can develop differently in the presence of a theory. Certain actions or tendencies may be emphasized (and others de- emphasized) and in this way gather a kind of strength or inertia that may ramify to affect how practice unfolds. Thus, Lewin's epigram is valuable for calling attention to the perhaps surprising role of theory as a context factor in the elaboration of new and possibly worthwhile forms of practice. But this interpretation of the epigram begs the further question of "what" is not so practical as a good theory. Viewed as a context in which practice may develop, one is left to wonder if theory is more practical than other narrative forms such as poetry, essays, or major works of fiction. Certainly, these too are important contexts of thinking and full of ideas that potentially relate to practice in the same way. It is not established and probably naive to insist that theory enjoys priority over these other narrative forms in deserving the appellation 'practical'.

Finally, and notwithstanding our doubts about the literal or even figurative validity of the epigram, we find that it may be justified by how it functions in the minds of practitioners. As noted above, belief in the practical value of theory can supply the confidence needed for action, and in this way (if no other) lead to opportunities to learn from actions taken. In other words, and somewhat paradoxically, even if untrue, the epigram may be self-fulfilling.

If we must have epigrams (as it seems we must), and if Lewin's does not say everything we'd like, then it may be time for a new one that is more faithful to 
our understanding. However, writing epigrams is not for the faint-hearted or timid. It is an arrogant art that few practice well, and most ought not attempt. This said, the author offers the reader this amendment of Lewin's original:

There is nothing so practical about theory (but it may be good to have around).

\author{
Lloyd E. Sandelands \\ Department of Psychology \\ The University of Michigan \\ $5^{80}$ Union Drive \\ Ann Arbor \\ $M I 4^{8100-1346}$
}

\title{
Acknowledgement
}

The author wishes to thank Dag Bjökegren, Art Brief, Tom D'Aunno, Janet Dukerich, Jane Dutton, Jim Larsen, Marjorie McCall, Mike Pratt, Rick Price, Anat Rafaeli, V. Srivatsan, Jim Walsh, Janet Weiss, members of the University of Michigan Seminar For Organization Studies, and the editor and reviewers of this journal for their helpful comments on earlier drafts of this manuscript.

\section{NOTES}

' This is a conceptual analysis of theory and practice as types of knowledge. It leaves aside empirical questions about who (e.g. theorists or practitioners) pursues or possesses which type of knowledge, or about how these types are psychologically represented and processed. Although important, these questions cannot be answered before coming to grips with the logical characteristics of these types.

${ }^{2}$ For an opposing view, see e.g., Bruner (1971). He identifies skills with performance programs guided by intentions:

Skilled activity is a program specifying an objective or terminal state to be achieved, and requiring the serial ordering of a set of constituent, modular subroutines. Functionally equivalent variations in serial order and substitution rules for constituent subroutines both are features of skilled activity and render skill productive in the sense that language is productive.

This concept of skill raises many questions. How are performance programs written? How is one chosen in one situation, and another one chosen in another situation? How is functional equivalence assessed? What rules govern use of substitution rules? And, perhaps most difficult of all, how does the program operating in the mind lead to execution of the skill in the body?

3 Curiously, Hume's view that causes are uninferred seems to fit existing research data better than the widely accepted competing view that causes are judgments. In particular, Michotte (1962) found that even brief, single exposures to an event are sufficient for people to say afterwards that causation occurred. This suggests that causality is directly perceived, and unreasoned. This recalls the arguments of radical 
empiricists such as James and Russell who maintained that relations are perceived just like objects. Today, however, this idea seems to have been lost - as indeed, the examples presented by Michotte are now named, ironically, "one-shot" causal inferences.

${ }_{4}$ The main solution to this problem has been to say that understanding proceeds in two directions at the same time - it flows both "top-down" (starting with a concept of the whole and proceeding to an interpretation of parts) and "bottom-up" (starting with parts and proceeding to a concept of the whole). The problem with this solution is that there are no details to support it. There is still the question of where the initial concept of the whole comes from (if not from some sort of information about parts); and still the question of how specific parts are picked out (if not on the basis of some sort of premonition or hypothesis about the whole). The appeal of this solution seems mainly the idea of parallel processing, which is borrowed from the metaphor of the digital computer (and this despite the notorious ineptness of the digital computer at perceiving things).

5 Despite the many problems of epistemology, scientific psychology often has followed its lead. For example, Bruner ( 1957 ) likened perception to hypothesis testing. Heider (1958) saw the psychology of interpersonal relations as a kind of naive epistemology. And Kelley (1973) compared attribution to statistical inference. Today, choice-making is identified with Boolean algebra and perception with psychometrics.

" This issue is more subtle than first appears. As Toulmin (1953) has pointed out, scientific writing cannot be blamed simply because it is obscure or inaccessible to the average reader. In order to avoid confusion and promote deeper understandings, new terms must be invented, and familiar old terms must be given new meanings. Sometimes the fault lies not with science, but with its readers who are unprepared to understand what the writing is about. Nevertheless, the specialized language of science is a problem when it prevents even the informed from seeing what is going on. Sixty years ago Eddington ( 1928 ) took physics to task for relying too much on pointer readings and high abstractions, and not enough on imaginable theory. Again today, there are calls for firmer footings, for understanding based on imaginable processes (see e.g., Gleick, 1987).

7 If this problem is obscure in Lewin's theoretical work it is perhaps because little of this work is actually explanatory. Lewin's main interest was not to develop a theory of psychology, but to develop a comprehensive and dynamic framework with which to describe psychological facts. This framework which he called 'field theory', and expressed in the terms of topological mathematics, was intended not as a theory or school of psychology, but as a tool for psychologists to use in building theories of behavior. A strong virtue of this language is that it is able to describe practically important facts of behavior in theoretically useful ways. Thus although field theory is a theory in name, it is not a theory in the sense of being an explanation. There is no problem of relating it to practice because it is not constituted in the form of a substantive theory.

${ }^{y}$ One might object that theory does lead to practice in the case of forecasting the future. But this brings us back to the logical type distinction discussed earlier. There is an important difference between a theory (which is a system of laws and antecedent conditions) and the understanding that produces it and allows us to draw logical deductions from it. Using theories to make predictions is itself a kind of practice.

9 Thus, this idea may be worth holding onto, in spite of doubts. However, as the example given by Argyris and Schon on bicycle riding showed, skills cannot be communicated by means of a theoretical or programmatic description. A similar conclusion is suggested by the fact that skills are lost through disuse; and sometimes beyond recovery (e.g. lost arts, old-world skills such as wheelwrighting, or certain kinds of blacksmithing, wood-working and stone-carving). 


\section{REFERENCES}

ARgYris, C. and Schon, D. (I974). Theory in practice: Increasing professional effectiveness. San Francisco: Jossey-Bass.

Arnheim, R. (1966). Toward a psychology of art. Berkeley, CA: University of California Press.

ARnheim, R. ( 1986 ). New essays on the psychology of art. Berkeley, CA: University of California Press.

Beyer, M.M. and TTrice, H.M. ( 1982 ). The utilization process: A conceptual framework and synthesis of empirical findings. Administrative Science Quarterly, 27, $59^{\mathrm{r}-622 .}$

Brown, R. (1976). Social theory as metaphor. Theory and Society, 3, 169-1 98.

Bruner, J. (1957). On perceptual readiness. Psychological Review, 4 I $23^{-1} 5^{2}$.

Bruner, J. (I97 I). The growth and structure of skill. In K.J. Connolly (ed.), Motor skills in infancy. New York: Academic Press.

Chomsky, N. ( 1972 ). Language and mind. New York: Harcourt.

Eddington, A.S. (r 928). The nature of the physical world. New York: Macmillan.

EMERson, R.W. (1903). "Nature." from, The complete works of Ralph Waldo Emerson. Boston: Harvard.

FEyerabend, P. (1987). Farewell to reason. London: Verso.

GleIck, W. ( 1987$)$. Chaos: $A$ new science in the making. New York: Harper and Row.

Hanson, N.R. ( 1969 ). Perception and discovery. San Francisco: Freeman.

HeIder, F. ( 1958). The psychology of interpersonal relations. New York: Wiley.

Hempel, C.G. and Oppenheim, P. (1948). The logic of explanation. Philosophy of Science, $\mathbf{I 5}$.

HUME, D. ( I 748/1955). An essay concerning human understanding. Indianapolis, IN: Bobbs-Merrill.

Kelley, H.H. (r 973). The process of causal attribution. American Psychologist, 28, $107^{-1} 28$.

KoHler, W. (1 947). Gestalt psychology. New York: Liveright.

LANGer, S.K. ( 1967). Mind: An Essay on Human Feeling. Baltimore, MD: Hopkins.

LEwIN, K. (1947). Frontiers in group dynamics. In D. Cartwright (eds.), Field Theory. NY: Harper.

MacIINTYRE, A. (1985). How psychology makes itself true (or false). In S. Koch and D. Leary (eds), A Century of Psychology as a Science. New York: McGrawHill.

Marrow, A. (I 969). The practical theorist. New York: Knopf.

Michotte, A. ( 1963 ). The perception of causality. New York: Basic Books.

Morgan, G. ( $\mathrm{I}^{8} 3$ ). More on metaphor: Why we cannot control tropes in administrative science. Administrative Science Quarterly, 28, 60 I-607.

Morgan, G. ( 1986). Images of Organization. New York: Sage. 
Polyani, M. (1967). The tacit dimension. Garden City, NY: Doubleday.

Palmer, S.E. (I975). Visual perception and word knowledge. In D.A. Norman, D.E. Rummelhart and the LNR Research Group. Explorations in cognition. San Francisco: Freeman.

Pinder, C.C. and Bourgeois, V.W. (1982). Controlling tropes in administrative science. Administrative Science Quarterly, 27, 64 I-652.

Quine, W.V. (1953). From a logical point of view. Cambridge, MA: Harvard.

Quine, W.V. ( 1981 ). Theories and things. Cambridge, MA: Belknap.

Roethlisberger, R.J. ( 1977 ). The elusive phenomena. Cambridge, MA; Harvard.

Ryle, G. (I 949). The concept of mind. Chicago: University of Chicago Press.

Sandel.ands, L.E. ( 1987 ). Task grammar and attitude. Motivation and Emotion, I I, I 2 I-I 43 .

Sandelands, L.E. and Drazin, R. (1989). On the language of organization theory. Organization Studies, $10(4), 457-478$.

SEARle, J. (1984). Minds, brains and science. Cambridge, MA: Harvard.

Susman, G.I. and EverED, R.D. ( 1978 ). An assessment of the scientific merits of action research. Administrative Science Quarterly, 23, 582-603.

TAYLOR, D.M. (1970). Explanation and meaning. Cambridge: University Press.

Toulmin, S. (I 953). The philosophy of science. London: Hutchinson.

TVersky, A. and Kahneman, D. (1974). Decision-making under uncertainty. Science, 185, I I $21-1$ I 34 .

WEICK, K.E. (I 969). The social psychology of organizing. Reading, MA: AddisonWesley.

Whetten, D.A. and Cameron, K.S. (1984). Developing Management Skills. Glenview, IL: Scott, Foresman.

Wittgenstein, L. ( I 953). Philosophical investigations. New York: Macmillan.

WORDsworth, W. (1864/1968). "The Prelude". Selected Poetry of William

Wordsworth. NY: Doubleday. 